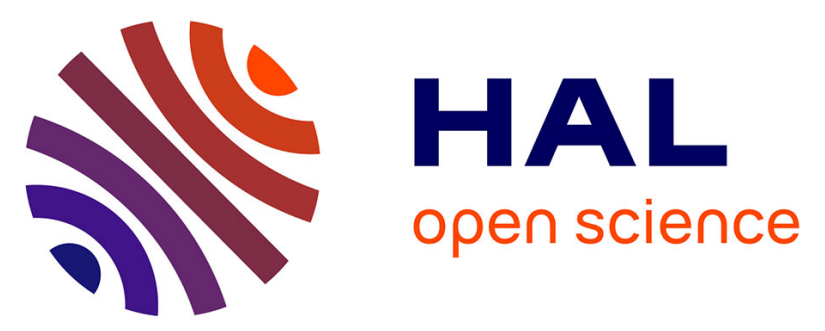

\title{
Association of HLA class I markers with Multiple Sclerosis in the Italian and UK population: evidence of two independent protective effects
}

Laura Bergamaschi, Maria Ban, Nadia Barizzone, Maurizio Leone, Maria Edvige Fasano, Franca R Guerini, Lucia Corrado, Paola Naldi, Ennia Dametto, Cristina Agliardi, et al.

\section{To cite this version:}

Laura Bergamaschi, Maria Ban, Nadia Barizzone, Maurizio Leone, Maria Edvige Fasano, et al.. Association of HLA class I markers with Multiple Sclerosis in the Italian and UK population: evidence of two independent protective effects. Journal of Medical Genetics, 2011, 48 (7), pp.485. 10.1136/jmg.2010.080721. hal-00616879

\section{HAL Id: hal-00616879 \\ https://hal.science/hal-00616879}

Submitted on 25 Aug 2011

HAL is a multi-disciplinary open access archive for the deposit and dissemination of scientific research documents, whether they are published or not. The documents may come from teaching and research institutions in France or abroad, or from public or private research centers.
L'archive ouverte pluridisciplinaire HAL, est destinée au dépôt et à la diffusion de documents scientifiques de niveau recherche, publiés ou non, émanant des établissements d'enseignement et de recherche français ou étrangers, des laboratoires publics ou privés. 
Association of HLA class I markers with Multiple Sclerosis in the Italian and UK population: evidence of two independent protective effects

Laura Bergamaschi ${ }^{1}$, Maria Ban ${ }^{2}$, Nadia Barizzone ${ }^{1}$, Maurizio Leone ${ }^{3}$, Daniela Ferrante ${ }^{4}$, Maria Edvige Fasano ${ }^{5}$, Franca R Guerini ${ }^{6}$, Lucia Corrado ${ }^{1}$, Paola Naldi ${ }^{3}$, Ennia Dametto ${ }^{5}$, Cristina Agliardi ${ }^{6}$, Marco Salvetti ${ }^{7}$, Rosella Mechelli ${ }^{7}$, Daniela Galimberti ${ }^{8}$, Elio Scarpini ${ }^{8}$, Paola Cavalla ${ }^{9}$, Valeria Bargiggia ${ }^{10}$, Domenico Caputo ${ }^{11}$, Susanna Cordera ${ }^{12}$, Francesco Monaco ${ }^{13}$, Patricia Momigliano-Richiardi ${ }^{1}$, Sandra D'Alfonso ${ }^{1}$

${ }^{1}$ Department of Medical Sciences and Interdisciplinary Research Center of Autoimmune Diseases (IRCAD), University of Eastern Piedmont, Novara, Italy

${ }^{2}$ University of Cambridge, Department of Clinical Neuroscience, Addenbrooke's Hospital, Hills Road, Cambridge, CB2 0QQ, UK

${ }^{3}$ Department of Neurology, A.O.U. Maggiore della Carità, and IRCAD, Novara, Italy

${ }^{4}$ Department of Medical Sciences, Unit of Medical Statistics and Cancer Epidemiology, University of Eastern Piedmont and CPO Piemonte, Novara, Italy

${ }^{5}$ SCDU Transplantation Immunology, A.O.U. S. Giovanni Battista di Torino, Turin, Italy

${ }^{6}$ Laboratory of Molecular Medicine and Biotechnologies, Don C. Gnocchi Foundation IRCCS, S. Maria Nascente, Milan, Italy

${ }^{7}$ Neurology and Center for Experimental Neurological Therapy (CENTERS), Università La Sapienza, Rome, Italy

${ }^{8}$ Department. of Neurological Sciences, University of Milan, Dino Ferrari Center, Fondazione Cà Granda, IRCCS Ospedale Maggiore Policlinico, Milan , Italy

${ }^{9}$ Multiple Sclerosis Center, A.O.U. S. Giovanni Battista di Torino, Department of Neurosciences, University of Turin, Turin, Italy

${ }^{10}$ Multiple Sclerosis Center, Neurological Institute C. Mondino, IRCCS, Pavia, Italy.

${ }^{11}$ Multiple Sclerosis Unit, Don C. Gnocchi Foundation, IRCCS, S. Maria Nascente, Milan, Italy

${ }^{12}$ Neurology, Ospedale Umberto Parini, Aosta, Italy

${ }^{13}$ Department of Neurology, A.O.U. Maggiore della Carità Novara, and Department of Clinical and Experimental Medicine, University of Eastern Piedmont, Novara, Italy

\section{Corresponding author:}

Sandra D'Alfonso

Department of Medical Sciences

Eastern Piedmont University

Via Solaroli 17

28100 Novara, Italy

Telephone: 39321 660606, Fax : 39321620421

Email: dalfonso@med.unipmn.it

KEYWORDS: multiple sclerosis, HLA class I markers, haplotypes, genetic association. 
WORD COUNT: 4221

Running title : HLA class I markers involved in MS susceptibility 


\section{ABSTRACT}

Background: We recently confirmed the association with Multiple Sclerosis (MS) of $H L A-A * 02$ and observed that the combined presence of $H L A-C w^{*} 05$ significantly enhanced (3-fold) the protective effect of $H L A A * 02$.

Objectives and Methods: Since $A * 02-C w^{*} 05$ is carried by two HLA extended haplotypes characterized by the $B * 4402$ and $B * 1801$ alleles, respectively, we extended the association analysis to HLA- $B * 44$ and $-B^{*} 18$ in our Italian sample (1445 MS cases and 973 controls) and verified these associations in a UK cohort (721 MS cases, 408 controls and 480 family trios).

Results: A strong protective effect, independent of $D R 15$, of the $A * 02-C w^{*} 05$ combination carrying $B^{*} 44\left(\mathrm{OR}=0.27 \mathrm{p}=3.3 \times 10^{-5}\right)$, was seen in the Italian samples and confirmed in UK family trios $\left(\mathrm{OR}=0.33 \mathrm{p}=5.5 \times 10^{-4}\right)$ and in a combined cohort of UK families and case/controls $(\mathrm{OR}=0.53$ $\mathrm{p}=0.044)$. This protective effect was significantly stronger than that mediated by $A * 02$ alone. Logistic regression showed that $A * 02-C w * 05$ maintained a significant protection when adjusted for $\mathrm{B}$ alleles (Italy: $\mathrm{OR}=0.38 \mathrm{p}=6.5 \times 10^{-7}$; UK: $\mathrm{OR}=0.60 \mathrm{p}=0.0029$ ) indicating that it was not secondary to linkage disequilibrium with $B^{*} 44$. At difference from $A * 02$, the other HLA class I tested markers individually showed no significant $\left(C w^{*} 05, B^{*} 18\right)$ or a modest $\left(B^{* 44}\right)$ protection when adjusted for the remaining markers.

Conclusions: We identified at least two independent protective effects which are tagged by $A * 02$ $C w * 05$ and $A * 02$, respectively. Further studies are needed to elucidate whether this protective effect is due to the presence of an unanalyzed factor characterizing the HLA extended haplotype/s carrying $\mathrm{A} * 02$ and $\mathrm{CW}^{*} 05$ or to a direct interaction between these alleles. 


\section{INTRODUCTION}

Multiple Sclerosis (MS) is a complex disease characterized by inflammatory foci in the central nervous system (CNS) causing a progressive demyelination of axons and neuronal cell degeneration, resulting in a severe disabling condition.

The pathogenesis of MS is not well understood, but it is well established that both genetic and environmental factors contribute together to the development of the disease.

Association with the human leukocyte antigen (HLA) genes from the major histocompatibility complex on chromosome 6p21.3 was identified almost 40 years ago. It is well established that the $H L A-D R B 1 * 1501$ allele, tagging the $D R B 1 * 1501-D Q B 1 * 0602$ (also known as DR15) haplotype in the HLA class II region, is the strongest genetic risk factor conferring an OR of approximately 3 in most studied populations. [1-4]

Through careful analysis of this complex region, which is characterized by an extreme polymorphism and extensive linkage disequilibrium, evidence for an independent effect on risk from the class I region has emerged. In 2007, IMSGC presented data from a large study based on UK and North American Caucasians suggesting that this signal might be determined by the $H L A$ $C w^{*} 05$ allele. The $H L A C w^{*} 05$ allele was less frequent in patients than controls conferring a protective effect.[5] At the same time, two other groups identified an association between the $H L A$ $A * 02$ allele and MS with a similar OR in two populations (Swedish and Tasmanians) with a different genetic background. This allele, like $H L A C w^{*} 05$, conferred a protective effect.[6, 7]

We recently tested the association of both $H L A A * 02$ and $H L A C w^{*} 05$ in an Italian cohort of 1273 MS patients and 1075 controls.[8] Our analyses confirmed the protective effect of $H L A A^{*} 02$ whereas $H L A C w^{*} 05$ did not present any independent association. However, the presence of $H L A$ $C w^{*} 05$ appeared to significantly enhance the protective effect due to $H L A A * 02$ resulting in a 3 fold decreased OR for the $H L A A^{*} 02-C w^{*} 05$ combination $(\mathrm{OR}=0.22,95 \% \mathrm{CI}: 0.13-0.38)$ relative to the presence of $H L A A^{*} 02$ alone $(\mathrm{OR}=0.69,95 \% \mathrm{CI}: 0.58-0.83)$. In the Caucasian population, the $H L A A * 02-C w * 05$ combination is carried by two HLA extended haplotypes, namely $H L A A * 0201$ $C w^{*} 0501-B * 4402-D R B 1 * 0401$ and HLA $A * 0201-C w^{*} 0501-B * 1801-D R B 1 * 1102$ (also known as 44.1 and 18.3 haplotypes, respectively, [9-11]). These two haplotypes are present in the Italian population with approximately the same frequency (Rendine, unpublished). Thus it is possible that the strong protective effect we detected for the $\mathrm{A}^{*} 02-\mathrm{Cw} * 05$ combination is due to a haplotypic effect, i.e. to the presence of a primarily associated factor carried by one or both the above haplotypes. Interestingly $H L A B^{*} 4402$ was recently identified as an MS protective factor.[12, 13, 14] 
In order to better understand whether the enhanced protective effect of the $H L A A * 02-C w * 05$ combination is due to a haplotypic effect or a direct interactive role of the two markers as well as test the possible role of $B * 44$, in the present study we extended the analysis in our Italian cohort to the involved $H L A-B$ alleles, namely $H L A B^{* 44}$ (and its subtypes $B^{* 4402}$ and $B^{* 4403}$ ) and $B^{*} 18$. The association with MS of the various haplotypic combinations of the $A * 02-C w^{*} 05$ set with or without $B^{*} 44$ or $B^{*} 18$ was also analysed in a UK cohort fully typed for HLA-DR, -A,-B and -C, in order to verify our results in another population with a possibly different genetic background.

\section{MATERIALS AND METHODS}

\section{Subjects}

A total of 1445 Italian MS patients and 973 controls were analyzed for $H L A-A * 02,-C w * 05,-B * 18$ and $-B * 44$ class I markers and for DRB1*15. Of these, 1433 patients and 950 controls were also typed for $B^{* 44}$ subtypes (4402 and 4403). The majority of the samples were recruited from North-

West Italy and the remaining from Central Italy. Patients with Sardinian ancestors were excluded to avoid the introduction of a confounding source of heterogeneity.

Italian controls included medical students, university and hospital staff, blood donors (female:male ratio 1:1.1) matched for age and regional origin with the MS patients.

Patients (83\%) and controls (91\%) mostly overlap with those included in our previous paper [8] and were already typed for $H L A-A * 02, C w^{*} 05$ and $D R B 1 * 15$. Selection for inclusion was based on DNA availability.

We also analysed a UK data set composed of 721 MS patients, 408 healthy matched controls and 480 family trios. These samples were described in detail elsewhere.[5]

Patients were diagnosed according to McDonald et al. criteria.[15] All the samples, both Italian and British, were of European ancestry.

Features of the analyzed samples are shown in Table 1. All the samples were collected after informed consent and appropriate ethical approvals.

\section{HLA typing of Italian samples}

HLA typing was performed using specific reactions in order to obtain information about the four HLA class I markers (HLA-A*02, $-C w * 05,-B * 44$ and $-B * 18)$ and $D R B 1 * 15$.

The methods used to analyze $H L A-A * 02, H L A-C w^{*} 05$ and $D R B * 15$ were described in detail elsewhere.[8] 
$H L A B^{*} 44$ and $H L A B^{*} 18$ were analyzed by two distinct allele specific PCR reactions following the conditions of the $12^{\text {th }}$ International Histocompatibility Workshop.[16] Specific primer pairs were used to amplify HLA $B^{* 44}$ (Forward: 5'- TACCGAGAGAACCTGCGC -3', Reverse: 5'CCAGGTATCTGCGGAGCG -3', producing a fragment of $541 \mathrm{bp}$ ) and a $250 \mathrm{bp}$ internal control fragment (Forward: 5'- ATGATGTTGACCTTTCCAGGG -3', Reverse: 5' ATTCTGTAACTTTTCATCAGTTGC -3'). The reaction mix contained $0.027 \mathrm{U} / \mu \mathrm{l}$ GoTaq (Promega), $0.83 \mathrm{pmol} / \mu \mathrm{l}$ of $H L A-B * 44$ specific primers, $0.33 \mathrm{pmol} / \mu \mathrm{l}$ of internal control primers, 2 $\mathrm{mM}$ of $\mathrm{MgCl}_{2}$ and $0.2 \mathrm{mM}$ dNTPs. The $B * 44$ subtypes $B * 4402$ and $B * 4403$ were typed by two distinct nested allele specific PCR reactions, utilizing an $H L A B^{*} 4402$ specific (5'CTCCAGGTAGGCTCTGTC -3') and an HLA $B^{*} 4403$ specific (5'- CTCCAGGTAGGCTCTCAC -3') reverse primer respectively. The same forward primer and the same internal control as $H L A$ $B * 44$ was used in both reactions. The specific product size was $507 \mathrm{bp}$. Both reactions were performed with the same reaction mix, containing $0.025 \mathrm{U} / \mu \mathrm{l} \mathrm{GoTaq}$ (Promega), $0.83 \mathrm{pmol} / \mu \mathrm{l}$ of $H L A-B * 4402 / H L A-B * 4403$ specific primers, $0.33 \mathrm{pmol} / \mu \mathrm{l}$ of internal control primers, $2 \mathrm{mM}$ of $\mathrm{MgCl}_{2}$ and $0.2 \mathrm{mM}$ dNTPs. The HLA $B * 44$ PCR product, at a 1:100 dilution factor, was used as template. $H L A B^{*} 18$ typing was performed by specific primers which allowed to amplify only the HLA $\quad B^{*} 18$ allele (Forward: 5' - TACCGAGAGAACCTGCGC -3', Reverse: 5' CCAGGTATCTGCGGAGCG -3', producing a fragment of $490 \mathrm{bp}$ ) with the same internal control as $H L A B^{*} 44$. The reaction mix contained $0.027 \mathrm{U} / \mu \mathrm{l}$ GoTaq (Promega), $1 \mathrm{pmol} / \mu \mathrm{l}$ of $H L A B^{*} 18$ specific primers, $1 \mathrm{pmol} / \mu \mathrm{l}$ of internal control primers, $2 \mathrm{mM}$ of $\mathrm{MgCl}_{2}$ and $0.2 \mathrm{mM} \mathrm{dNTPs}$.

All these protocols, with the exception of $A * 02$, did not allow to distinguish between homozygotes and heterozygotes but only whether the samples were positive or negative for the tested markers.

These methods were validated testing 45 samples previously typed with standard protocols. The results were consistent for all tested samples.

\section{HLA class I and class II typing of UK samples}

All the UK samples had been previously completely typed for the HLA-A, $-C,-B$ and $-D R B 1$ loci as described in detail elsewhere. [5]

The trio families were genotyped with a medium resolution method for all HLA class I (two-digit) and class II (four-digit) alleles. In particular for the HLA-B locus, all the family members were typed for both $H L A-B * 12$ subtypes, namely $B * 44$ and $B * 45$. The case/control samples were analyzed with a low resolution method for all class I and class II alleles. This method did not allow discrimination between the two $H L A-B^{*} 12$ subtypes. However, since $B^{* 44}$ is by far the most frequent $B^{*} 12$ subtype in the British population $(0.185$ versus 0.006 in the non transmitted 
haplotypes of the 480 family trios) and is in strong linkage disequilibrium with $C w^{*} 05$ (D’ $=0.85$, $\mathrm{r}^{2}=0.66$, Fig. 1 , it is likely that most $B^{*} 12$ positive and practically all $B^{*} 12-C w^{*} 05$ positive individuals were $B * 44$ positive.

\section{Statistical analysis}

The association of each marker, haplotype or phenotype combination with the disease was measured by $\chi^{2}$ test, the Odds Ratio (OR) and its $95 \%$ Confidence Intervals (95\% CI). Allele and haplotype analyses of UK samples were performed with the UNPHASED v 3.0.13 program using the "certain haplotype only" option for family trios and the "uncertain haplotypes" option for the case/control cohort.[17]

Linkage disequilibria (LD) were calculated from phenotypes according to Mattiuz et al. [18].

Logistic regression was carried out to determine the effect of the considered markers on MS susceptibility. The association of each polymorphism with the disease was measured by the Odds Ratio (OR) and its 95\% Confidence Intervals (95\% CI). We used likelihood ratio tests (LRT) to assess the statistical significance of the models and to compare the models. The contribution of each variable was evaluated by comparing the LRTs derived from a model with and without the variable. Reported $\mathrm{p}$ values were not corrected for the number of comparisons.

\section{RESULTS}

\section{Case/Control association analysis in the Italian population.}

A total of $1445 \mathrm{MS}$ patients and 973 controls, previously typed for $H L A-D R B 1 * 15, A * 02$ and $C w^{*} 05$, were further typed for $B * 18$ and $B * 44$. A schematic map of the HLA genes analysed in this study is shown in Figure 1 together with the pairwise linkage disequilibria (LD) between the tested alleles. The association with MS of the different phenotypic combinations carrying both $H L A-A * 02$ and $H L A-C w^{*} 05\left(A * 02-C w^{*} 05\right)$ with or without $B * 18$ and $B * 44$ was then analysed (Table 2$)$. The complete results including all the other possible combinations of $H L A-A,-B,-C$ tested alleles are shown in the Supplementary Table 1.

$A * 02-C w^{*} 05$ conferred a strong protection particularly in the presence of $B * 44(\mathrm{OR}=0.28 ; \mathrm{p}=$ $\left.4.1 \times 10^{-6}\right)$ but also of $B^{*} 18(\mathrm{OR}=0.41 ; \mathrm{p}=0.004)$. Conversely, in their absence, the protection conferred by $A^{*} 02-C w^{*} 05$ was weaker and not statistically significant, although, owing to the low frequency of this combination, this analysis had only limited power $(\alpha=0.05 ; \beta=0.21)$ and cannot be considered informative. The OR values for the different phenotypic combinations in the whole population and in DR15 negative individuals were substantially the same (Table 2). 


\section{Association analysis in UK family trios}

To confirm and extend the results obtained in the Italian case/control study, we analysed the association with MS of $A * 02-C w^{*} 05$ with or without $B * 44$ or $B * 18$ in a panel of 480 family trios from the UK population fully typed for $H L A-D R,-A,-B$ and $-C$ at a medium resolution. This analysis would allow us to a) test the association of "certain" haplotypes, deduced by family segregation, and b) verify the results in a population with a different genetic background, i.e. different haplotype frequencies.

To eliminate the possible confounding effect of linkage disequilibrium (LD) with $H L A-D R B 1 * 15$, we considered the transmission of $D R B 1 * 15$-negative haplotypes only (Table 3 ). Pairwise LD values between $D R B 1 * 15$ and the tested HLA Class I markers in the UK population are shown in Figure 1.

The large majority of haplotypes carrying both $A * 02$ and $C w * 05$ were $B * 44$ positive and conferred a strong protection $\left(\mathrm{OR}=0.36 ; \mathrm{p}=5.5 \times 10^{-4}\right)$, comparable to that seen in the Italian population. The association with the $A * 02-C w^{*} 05-B * 44$ haplotype remained significant $(\mathrm{p}=0.0057)$ after conditioning on the DRB1 locus by the UNPHASED program, main effect option.

The $A * 02-C w * 05-B * 18$ and $A * 02-C w * 05-B * 44 / B * 18$ neg haplotypes were very rare in the UK population and would require testing of a much larger panel of families to yield informative results. The complete results including all the other possible combinations of $H L A-A * 02,-B * 44,-B * 18$ and $-C w * 05$ alleles are shown in the Supplementary Table 2.

\section{Dissection of the protective effect of the $\mathrm{A} * 02-\mathrm{Cw} * 05$ haplotypes}

To dissect the effect of the different components of the $A * 02-C w * 05$ protective combinations both in the Italian and UK samples we a) performed a logistic regression analysis and b) tested the association of all the possible combinations of the $A^{*} 02, C w^{*} 05$ and $B^{*}$ alleles. The same procedure was applied to the analysis both of Italian phenotypes and UK haplotypes.

a) For the logistic regression analysis (Table 4) all Italian individuals and UK haplotypes were categorized according to the presence or absence of each of the considered alleles $(A * 02, C w * 05$, $B * 18, B^{* 44)}$ and also of the $A * 02-C w^{*} 05$ combination. DRB1*15 was always included in the model. To increase the power of the UK study, haplotype frequencies deduced from an additional case-control dataset of the UK population were combined with those of family trios, with a total of 2106 case and 1676 control haplotypes (see note to Table 4) fully typed for $H L A-D R,-A,-B$ and $C$. This second UK database was typed for $B^{*} 12$ instead of $B^{*} 12$ subtypes, $B * 44$ and $B * 45$ (see Materials and Methods). 
In the Italian sample, the significant protection conferred by $A * 02(\mathrm{OR}=0.63 ; \mathrm{CI} 95 \% 0.53-0.74)$ and by the $A * 02-C w * 05$ combination ( $\mathrm{OR}=0.39$; CI95\% 0.27-0.57) remained similar after accounting for $B * 44$ and $B * 18$. In addition we observed a significant protective effect for $B * 44(\mathrm{OR}=0.70$; CI95\% 0.56-0.88) that was not substantially modified by adjustment for the other markers included in the model. No significant effect was detected for $B * 18$ and for $C w * 05$. The contribution to the model of $A * 02$ and of $A^{*} 02-C w^{*} 05$ relative to $B^{*} 44$, as calculated by the Likelihood Ratio Test (LRT), was highly significant $\left(\mathrm{p}=1.3 \times 10^{-7}\right.$ and $\mathrm{p}=7.3 \times 10^{-6}$ respectively). As for $B^{*} 44$, its contribution was still significant but weaker relative to the effect of $A^{*} 02(\mathrm{p}=0.005)$ and borderline relative to $A * 02-C w^{*} 05(\mathrm{p}=0.050)$.

In the UK sample we replicated the protective effect of $A * 02(\mathrm{OR}=0.72$; CI95\%0.62-0.83) and of $A * 02-C w * 05$ (OR=0.56; CI95\% 0.42-0.76) which remained similar after accounting for the other markers. $A * 02$ showed a significant contribution to the model relative to $C w^{*} 05(\mathrm{p}=0.0003)$ and $B * 12(\mathrm{p}=0.00013)$, while, at difference from Italians, the $A * 02-C w^{*} 05$ combination yielded only a modest $\left(\mathrm{p}=0.0272\right.$ ) contribution relative to $B^{*} 12 . B^{*} 12$, in its turn, showed a significant protection (OR=0.70; CI95\% 0.58-0.85) which was not modified by adjustment for $A * 02$ but whose contribution was no longer significant after accounting for $C w * 05(\mathrm{p}=0.06)$. The contribution of $B * 12$ to MS protection maintained a borderline effect relative to $A * 02-C w * 05$ ( $\mathrm{p}=0.047)$, similarly to what seen in the Italian sample. The protection of $C w^{*} 05$ was statistically significant, at difference from the Italians, but it was no longer significant after adjustment for $B^{*} 12(\mathrm{p}=0.06)$ or both $B^{*} 12$ and $A^{*} 02$ ( $\left.\mathrm{p}=0.21\right)$. No protective effect was observed for $B^{*} 18$.

To elucidate whether the effect of $A * 02-C w^{*} 05$ was distinct from that of $A * 02$ alone, we analysed the odds ratio of the $A * 02+C w^{*} 05+$ vs the $A * 02+C w * 05$ - combination. The combined presence of $A * 02$ and $C w^{*} 05$ was significantly more protective than $A * 02$ without $C w^{*} 05$ in both populations (Italy: $\mathrm{OR}=0.49,95 \% \mathrm{CI}=0.34-0.73, \mathrm{p}=0.0004$; UK: $\mathrm{OR}=0.69,95 \% \mathrm{CI}=0.50-0.95, \mathrm{p}=0.023$ ),

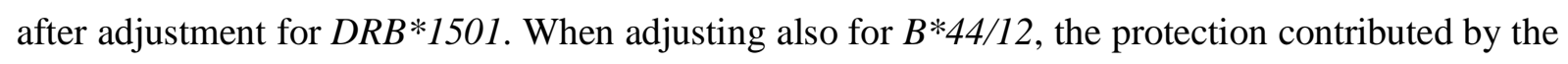
$A * 02+C w^{*} 05+$ combination remained significantly higher than that of $A * 02$ without $C w^{*} 05$ in the Italian population $(\mathrm{OR}=0.55,95 \% \mathrm{CI}=0.37-0.82, \mathrm{p}=0.003)$ while it was no longer significant in $\mathrm{UK}(\mathrm{p}=0.3)$.

The above results indicate the presence of three distinct protective effects, namely $A * 02-C w^{*} 05$, $A * 02$ and $B * 44$ with a decreasing protective strength While this is evident in Italians, in the UK population only two effects are clearly detectable since it is not possible to distinguish the effect of $B * 12$ from that of $A * 02-C w^{*} 05$. This is likely explained by the fact that most (>90\%) $A * 02-C w^{*} 05$ haplotypes carry $B * 44$ in the British as against about $50 \%$ in the Italian population. 
b) In order to better understand the effect of the different allele combinations we tested their association in DR15 negative Italian (1005 MS cases and 848 controls) and UK (261 MS patients, 293 controls and 131 DR15 negative families) samples. The complete results including all the possible combinations of $H L A-A * 02,-B * 44,-B * 18$ and $-C w^{*} 05$ alleles of the Italian and British data sets are shown in the Supplementary Tables 1, 2, 3 and 4.

A comparison of the results of the various tested populations and data sets is summarized in Table 5. $H L A-B^{*} 18$ was not included because in the British population some of its combinations with $A * 02$ and $C w^{*} 05$ were very rare and none was significantly associated to MS (Table 3 and Supplementary Tables 2, 3,4) and in both populations the logistic regression analysis ruled out a protective role of this marker (Table 4).

The main conclusions that can be drawn from Table 5 are the following:

- The $A * 02-C w^{*} 05-B * 44 / 12$ combination conferred a significant protection in both populations. Actually, this was the only allele combination consistently associated in both populations and in all the tested panels.

- A significant protection was also observed for the $C w^{*} 05-B * 12$ combination in the absence of $A * 02$, but only in the UK case/control $(\mathrm{OR}=0.31,95 \% \mathrm{CI}: 0.10-0.81, \mathrm{p}=0.0324$, Supplementary Table 3) and combined haplotype $(\mathrm{OR}=0.37, \mathrm{p}=0.0087)$ panels.

- The $A * 02-C w * 05$ combination in the absence of $B * 44$ was significantly protective only in the Italian population $(\mathrm{OR}=0.36, \mathrm{p}=0.007)$. This haplotypic combination was practically absent $(<1 \%)$ in the British population (supplementary Tables 2, 3, 4).

- In both populations $A * 02$ also conferred a significant protection in the absence of $C w * 05$ and $B * 44$. The OR conferred by $A * 02$ was significantly different from that of the $A * 02-C w * 05-B * 44$ combination in the DR15 negative Italian dataset $(\mathrm{p}=0.002)$ and in the UK family trios $(\mathrm{p}=0.007)$ suggesting the presence of two distinct protective effects, while this difference was not statistically different in the UK case- control cohort.

- $B * 44$ in the absence of $A * 02-C w * 05$ consistently showed OR values <1 although, at difference from the logistic regression results, the lower number of included samples (only those DR15 negative) did not allow to reach statistical significance. In the Italian samples it was possible to test the association with MS also of the two $B * 44$ subtypes (B*4402 and $B * 4403)$, (Supplementary Table 1). The two subtypes were differently distributed according to the presence or absence of $C w^{*} 05$ : about $86 \%$ of $C w^{*} 05$ positive as against about $35 \%$ of $C w^{*} 05$ negative individuals were $B * 4402$, similarly in patients and in controls. In the absence of $A * 02-C w^{*} 05$ neither of the two $B * 44$ subtypes was significantly associated with MS (Supplementary Table 1). 
- $C w^{*} 05$, in the absence of $A * 02$ and $B * 44$, was not significantly protective in any of the tested data sets. On the contrary, in the Italian population it behaved as a strong risk factor, confirming our previous results.[8]

\section{DISCUSSION}

This work stems from our previous study which found that the combination of two HLA class I alleles, $H L A-A * 02$ and $-C w^{*} 05$, conferred a significantly stronger protective effect towards MS than $A * 02$ alone.[8] The $A * 02-C w^{*} 05$ combination is carried by two HLA extended haplotypes, namely 44.1 ([HLA $\left.A * 0201-C w^{*} 0501-B * 4402-D R B 1 * 0401\right]$ and $18.3\left[H L A A * 0201-C w^{*} 0501-B * 1801\right.$ $D R B 1 * 1102]$, respectively. Our result was particularly intriguing since a strong protective association with the $B * 4402$ allele characterizing the 44.1 haplotype was recently reported in three studies.[12, 13, 14] Several interpretations of these results were possible: i) the stronger protection we detected for $A * 02-C w^{*} 05$ was secondary to linkage disequilibrium with $B * 4402$; ii) a primarily involved protective factor is carried by the 44.1 haplotype; iii) the presence of an epistatic interaction (i.e. an interaction between 2 alleles (in cis or trans) in which the risk associated with a particular allele depends on the presence or absence of a second allele,[19]) between $A * 02$ and $C w^{*} 05$ and/or $B * 4402$.

To answer to these questions we evaluated the association of the above involved HLA markers in two genetically different populations. Specifically, in the UK population the $A * 02-C w * 05$ positive combination is carried mostly by the $A * 02-\mathrm{C} w * 05-B * 44$ haplotype (91\% of $A * 02-C w * 05$ control haplotypes) while, the Italian $A * 02-C w^{*} 05$ positive individuals frequently carry this combination also with $B^{*} 18(41 \%)$ or in the absence of both B markers $(8 \%)$.

The typing strategy utilized for the Italian sample did not distinguish homozygotes from heterozygotes, making it impossible to deduce the haplotypic combinations of the tested alleles. Therefore the detected associations were with phenotypic rather than haplotypic allele combinations and it was not possible to determine whether the involved alleles were carried in cis or in trans. The second population compensated for this limitation, since in the UK samples it was possible to determine the allele phase, either by family segregation (trios) or by computer algorithms (casecontrol).

Association analysis in the Italian population showed a very strong protective effect of the $A * 02$ $C w^{*} 05-B * 44$ phenotypic combination, independently of $D R B 1 * 15$. The protective effect of the $A * 02-C w^{*} 05-B * 44$ haplotype was replicated in British family trios and shown to be independent of DRB1 locus. In this dataset the $A * 02-C w^{*} 05-B * 44$ haplotype conferred a protection similar to the effect observed for the phenotypic allele combination in Italy. In both populations the protection 
was significantly higher than that of $A * 02$ alone, i.e. in the absence of $C w^{*} 05$ and $B 44(\mathrm{p}=0.002$ and 0.007 respectively in Italy and UK trios), indicating two distinct protective effects.

The logistic regression analysis showed that the $A * 02-C w * 05$ combination maintained a significant protective effect in both populations when adjusting for the B locus indicating that this effect was not secondary to linkage disequilibrium with $B^{*} 44$. Moreover, in the Italian population $A * 02$ $C w^{*} 05$ maintained a significant protective effect also in the absence of $B * 44$, suggesting that this effect was not restricted to the $A * 02-C w^{*} 05-B * 44$ combination. This result cannot be replicated in the UK sample though, since the $A * 02-C w * 05$ combination without $B * 44$ is virtually absent in this population. Finally, $\mathrm{A} * 02-\mathrm{Cw} * 05$ was significantly more protective than $A * 02$ without $C w * 05$ in both populations.

In both populations $B^{*} 44$ showed significant protection independent of the $A * 02$ effect, paralleling the result recently published in a US sample. However, $B * 44$ maintained only a borderline effect relative to $A * 02-C w^{*} 05$, indicating that most of its protection is mediated by the haplotype. The recent studies $[12,13,14]$ reporting the protection of $B * 44$ did not evaluate the effect of the $A * 02$ $C w^{*} 05$ haplotype. Since two of the above studies $[12,13]$ included a large overlap of individuals from UK where the majority of $A * 02-C w^{*} 05$ haplotypes also carry the $B * 44$ allele, it is possible that their data indicate the same effect observed in the present paper. These results highlight the importance of testing the association of allele combinations in addition to single alleles within the HLA region as well as highlight the usefulness of testing populations with different haplotype frequencies to dissect the associated alleles.

The protective effect of $C w^{*} 05$ evident in the UK population was not replicated in the Italian sample and was not distinguishable from that of $B^{*} 44$ because the LD between these two markers is particularly high in the UK population (Figure 1). While our results clearly show that the $A * 02$ $C w * 05$ combination maintains a protective effect independently of the tested $\mathrm{B}$ alleles, we were not able to elucidate whether this protective effect was due to the presence of a non analyzed factor characterizing the HLA extended haplotype/s carrying $A^{*} 02$ and $C w^{*} 05$ (haplotypic effect) or to a direct interaction between the two alleles. There is a preliminary indication in favour of the "haplotypic effect" hypothesis derived from the observation that the $C w * 05-B * 44$ haplotype not carrying $A^{* 02}$ still maintains a significant protective effect. This result would be against the hypothesis of an $A * 02 / C w^{*} 05$ interaction and indicates the presence of a protective factor in the region of the haplotype closer to $H L A-B$ and $H L A-C$ loci. However, this information mainly comes from the UK case/control data set where the haplotypic combinations are not certain (ascertained through family segregation) but are deduced by an algorithm. 
Further studies are needed to definitively demonstrate which of the two hypotheses is correct. A direct cooperation between $\mathrm{A} * 02$ and $\mathrm{Cw}^{* 05}$ molecules in MS protection remains an attractive hypothesis since they present antigenic peptides and interact with NK receptors.[20, 21]. Evidence in other autoimmune or infective diseases indicate that molecules encoded by different HLA loci might cooperate in the disease mechanism.[19, 22, 23] A direct functional effect of $\mathrm{A} * 02$ is suggested by recent results showing that $\mathrm{A} * 02$ prevents an MS-like disease in transgenic humanized mice.[24]

In conclusion, this study contributes to the demonstration that the HLA class I region contains additional factors modulating MS susceptibility, independently of the well established DRBI locus. At least two independent protective effects are proposed which are tagged by the $A * 02-C w * 05$ combination and the $A * 02$ allele, respectively. The protective effect of the $A * 02-C w^{*} 05-B * 44$ haplotype has a strength comparable to that of $D R B 1 * 15$, which is the strongest MS risk factor, thus behaving as an important modulator of MS susceptibility. The $A * 02-C w^{*} 05-B 44$ combination is relatively rare in both tested populations $(4.6 \%$ and $15.0 \%$ of DR15 negative Italian and British controls respectively). However, it is likely that its highly protective effect is genuine, and not a spurious signal due to its low frequency or to stratification, since it was replicated in two independent samples belonging to two populations with a different genetic background.

The identification of the primarily associated factor/s requires an extended analysis of the involved haplotype/s in populations with different genetic background. This will help to elucidate the mechanism mediating the protective effect and hence to shed new light on MS pathogenesis.

\section{ACKNOWLEDGEMENTS}

This work was supported by: the Italian Foundation for Multiple Sclerosis (FISM grants 2001/R/44, 2002/R/40 and 2005/R/10, 2008/R/11); CARIPLO Foundation, Regione Piemonte Ricerca Sanitaria Finalizzata (grants 2003 2004, 2007, 2008, 2009), Regione Piemonte CIPE 2004, Italian MIUR Ministry (PRIN 2008), Italian Ministry of Health (ricerca finalizzata grant 2004.80, "Giovani Ricercatori 2008”, Ricerca Corrente 2008-2009), Eastern Piedmont University, Compagnia di San Paolo (Turin), Fondazione CRT (Turin), Cambridge NIHR Biomedical Research Centre.

NB and LC were supported by a fellowship from FISM (2003/B/2, 2009/B/1). L.B. was supported by a PhD Lagrange Fellowship.

We are grateful to the patients and their parents. 


\section{REFERENCES:}

1. Ballerini C, Guerini FR, Rombola G, Rosati E, Massacesi L, Ferrante P, Caputo D, Talamanca LF, Naldi P, Liguori M, Alizadeh M, Momigliano-Richiardi P, D'Alfonso S.. HLA-multiple sclerosis association in continental Italy and correlation with disease prevalence in Europe. J Neuroimmunol 2004; 150: 178-85.

2. Fogdell A, Hillert J, Sachs C, Olerup O. The multiple sclerosis- and narcolepsy-associated HLA class II haplotype includes the DRB5*0101 allele. Tissue Antigens 1995; 46: 333-6.

3. Olerup O, Hillert J.HLA class II-as sociated genetic susceptibility in multiple sclerosis: a critical evaluation. Tissue Antigens 1991; 38: 1-15.

4. Barcellos LF, Sawcer S, Ramsay PP, Baranzini SE, Thomson G, Briggs F, Cree BC, Begovich AB, Villoslada P, Montalban X, Uccelli A, Savettieri G, Lincoln RR, DeLoa C, Haines JL, Pericak-Vance MA, Compston A, Hauser SL, Oksenberg JR. Heterogeneity at the HLA-DRB1 locus and risk for multiple sclerosis. Hum Mol Genet 2006; 15: 2813-24.

5. International Multiple Sclerosis Genetics Consortium (IMSGC). A second major histocompatibility complex susceptibility locus for multiple sclerosis. Ann Neurol 2007; 61: 228-36.

6. Brynedal B, Duvefelt K, Jonasdottir G, Roos IM, Akesson E, Palmgren J, Hillert J. HLA-A confers an HLA-DRB1 independent influence on the risk of multiple sclerosis. PLoS One 2007; 2: e664.

7. Burfoot RK, Jensen CJ, Field J, Stankovich J, Varney MD, Johnson LJ, Butzkueven H, Booth D, Bahlo M, Tait BD, Taylor BV, Speed TP, Heard R, Stewart GJ, Foote SJ, Kilpatrick TJ, Rubio JP. SNP mapping and candidate gene sequencing in the class I region of the HLA complex: searching for multiple sclerosis susceptibility genes in Tasmanians. Tissue Antigens 2008; 71: 42-50. 
8. Bergamaschi L, Leone MA, Fasano ME, Guerini FR, Ferrante D, Bolognesi E, Barizzone N, Corrado L, Naldi P, Agliardi C, Dametto E, Salvetti M, Visconti A, Galimberti D, Scarpini E, Vercellino M, Bergamaschi R, Monaco F, Caputo D, Momigliano-Richiardi P, D'Alfonso S. HLA-class I markers and multiple sclerosis susceptibility in the Italian population. Genes Immun 2010; 11:173-180.

9. Cattley SK, Williamson JF, Tay GK, Martinez OP, Gaudieri S,Dawkins RL. Further characterization of MHC haplotypes demonstrates conservation telomeric of HLA-A: update of the 4AOH and 10IHW cell panels. Eur J Immunogenet 2000; 27: 397-426.

10. Alper CA, Larsen CE, Dubey DP, Awdeh ZL, Fici DA, Yunis EJ. The haplotype structure of the human major histocompatibility complex. Hum Immunol 2006; 67: 73-84.

11. Dorak MT, Shao W, Machulla HK, Lobashevsky ES, Tang J, Park MH, Kaslow RA. Conserved extended haplotypes of the major histocompatibility complex: further characterization. Genes Immun 2006; 7: 450-467.

12. International MHC and Autoimmunity Genetics Network, Rioux JD, Goyette P, Vyse TJ, Hammarström L, Fernando MM, Green T, De Jager PL, Foisy S, Wang J, de Bakker PI, Leslie S, McVean G, Padyukov L, Alfredsson L, Annese V, Hafler DA, Pan-Hammarström Q, Matell R, Sawcer SJ, Compston AD, Cree BA, Mirel DB, Daly MJ, Behrens TW, Klareskog L, Gregersen PK, Oksenberg JR, Hauser SL. Mapping of multiple susceptibility variants within the MHC region for 7 immune-mediated diseases. Proc Natl Acad Sci U S A 2009; 106: 18680-5.

13. De Jager PL, Jia X, Wang J, de Bakker PI, Ottoboni L, Aggarwal NT, Piccio L, Raychaudhuri S, Tran D, Aubin C, Briskin R, Romano S; International MS Genetics Consortium, Baranzini SE, McCauley JL, Pericak-Vance MA, Haines JL, Gibson RA, Naeglin Y, Uitdehaag B, Matthews PM, Kappos L, Polman C, McArdle WL, Strachan DP, Evans D, Cross AH, Daly MJ, Compston A, Sawcer SJ, Weiner HL, Hauser SL, Hafler DA, 
Oksenberg JR. Meta-analysis of genome scans and replication identify CD6, IRF8 and TNFRSF1A as new multiple sclerosis susceptibility loci. Nat Genet 2009; 41: 776-82

14. Healy BC, Liguori M, Tran D, Chitnis T, Glanz B, Wolfish C, Gauthier S, Buckle G, Houtchens M, Stazzone L, Khoury S, Hartzmann R, Fernandez-Vina M, Hafler DA,Weiner HL, Guttmann CR, De Jager PL. HLA B*44: protective effects in MS susceptibility and MRI outcome measures. Neurology. 2010;75:634-40.

15. McDonald WI, Compston A, Edan G, Goodkin D, Hartung HP, Lublin FD, McFarland HF, Paty DW, Polman CH, Reingold SC, Sandberg-Wollheim M, Sibley W, Thompson A, van den Noort S, Weinshenker BY, Wolinsky JS. Recommended diagnostic criteria for multiple sclerosis: guidelines from the International Panel on the diagnosis of multiple sclerosis. Ann Neurol 2001; 50: 121-7.

16. Tonks S Marsh SGE, Bunce M, Moses JH, Krausa P, Sadler AM, Petronzelli F, Bodmer JG. "HLA class I DNA typing study". In: D. Charron (ed). Genetic Diversity of HLA: Functional and Medical Implications. EDK: Sevres 1997; 1:199-215 .

17. Dudbridge F. Likelihood-based association analysis for nuclear families and unrelated subjects with missing genotype data. Hum Hered 2008; 66: 87-98.

18. Mattiuz PL, Ihde D, Piazza A, Ceppellini R, Bodmer WD. New approaches to the population genetics and segregation analysis of the HLA system. In: P Terasaki (ed). Histocompatibility Testing. Munksgaard: Copenhagen, 1970, pp 193-205.

19. Lincoln MR, Ramagopalan SV, Chao MJ, Herrera BM, Deluca GC, Orton SM, Dyment DA, Sadovnick AD, Ebers GC. Epistasis among HLA-DRB1, HLA-DQA1, and HLA-DQB1 loci determines multiple sclerosis susceptibility. Proc Natl Acad Sci U S A 2009;106:7542-7.

20. Moretta L, Moretta A. Killer immunoglobulin-like receptors. Curr Opin Immunol 2004; 16:626-633.

21. Thananchai H, Gillespie G, Martin MP, Bashirova A, Yawata N, Yawata M, Easterbrook P, McVicar DW, Maenaka K, Parham P, Carrington M, Dong T, Rowland-Jones S. Cutting 
Edge: Allele-specific and peptide-dependent interactions between KIR3DL1 and HLA-A and HLA-B. J Immunol 2007; 178:33-7.

22. She JX. Susceptibility to type I diabetes: HLA-DQ and DR revisited. Immunol Today 1996; 17:323-9.

23. Carrington M, Nelson GW, Martin MP, Kissner T, Vlahov D, Goedert JJ, Kaslow R, Buchbinder S, Hoots K, O'Brien SJ. HLA and HIV-1: heterozygote advantage and B*35CW*04 disadvantage. Science 1999; 283:1748-52.

24. Friese MA, Jakobsen KB, Friis L, Etzensperger R, Craner MJ, McMahon RM, Jensen LT, Huygelen V, Jones EY, Bell JI, Fugger L.. Opposing effects of HLA class I molecules in tuning autoreactive CD8+ T cells in multiple sclerosis. Nat Med 2008; 14: 1227-1235. 


\section{FIGURE LEGEND}

Figure 1

Map of the HLA alleles analysed in this study and their linkage disequilibrium relationship.

Pairwise D', $\mathrm{r}^{2}$ and $\mathrm{p}$ values were calculated according to Mattiuz et al. [18] in the Italian (IT) and UK controls. Significant values are in boldface.

Regarding $B * 44 / B 12$, results are referred to $B^{*} 44$ for the Italians and $B^{*} 12$ for the UK. 


\section{Licence for Publication statement}

"The Corresponding Author has the right to grant on behalf of all authors and does grant on behalf of all authors, an exclusive licence (or non exclusive for government employees) on a worldwide basis to the BMJ Publishing Group Ltd to permit this article (if accepted) to be published in JMG and any other BMJPGL products and sublicences such use and exploit all subsidiary rights, as set out in our licence (http://group.bmj.com/products/journals/instructions-for-authors/licenceforms)."

\section{Competing Interest :}

"None to declare" 

Table 1: Characteristics of the patients

\begin{tabular}{ccccccccc}
\hline & & & & & & & \\
Origin & $\mathrm{N}$ & $\begin{array}{c}\text { Age at } \\
\text { Diagnosis }\end{array}$ & $\begin{array}{c}\text { Female:Male } \\
\text { Ratio }\end{array}$ & \multicolumn{3}{c}{ Disease Course (\%) } \\
\cline { 5 - 8 } & & & & & & & & \\
\hline Italy & 1445 & $31 \pm 10.5$ & $2: 1$ & 89 & 11 & 7 & 1 \\
UK & $1201^{\mathrm{a}}$ & $35.6 \pm 9.8$ & $2.8: 1$ & 57 & 34 & 9 & 0 \\
\hline
\end{tabular}

${ }^{\text {a }}$ of whom 480 with both parents

RR: Relapsing Remitting; SP: Secondary Progressive; PP: Primary Progressive; PR: Progressive Relapsing. 
Table 2: Combinations of the "HLA- $A * 02-H L A-C w^{*} 05$ " phenotype with $H L A-B$ in Italian MS patients and controls

\begin{tabular}{|c|c|c|c|c|c|c|}
\hline \multicolumn{2}{|c|}{ HLA phenotype $^{\mathrm{a}}$} & \multirow[t]{2}{*}{ Sample } & \multicolumn{2}{|c|}{ Frequency } & \multirow[t]{2}{*}{ OR $(95 \% \mathrm{CI})$} & \multirow[t]{2}{*}{$P$ value ${ }^{C}$} \\
\hline$A * 02-C w * 05$ & $B^{* \mathrm{~d}}$ & & MS patients & Controls & & \\
\hline & & total & $\mathrm{N}=1445$ & $\mathrm{~N}=973$ & & \\
\hline+ & - & & 0.008 & 0.013 & $0.59(0.24-1.41)$ & 0.317 \\
\hline+ & 44 & & 0.013 & 0.044 & $0.28(0.15-0.50)$ & $4.1 \times 10^{-6}$ \\
\hline+ & 18 & & 0.014 & 0.032 & $0.41(0.22-0.75)$ & 0.0040 \\
\hline \multirow{2}{*}{\multicolumn{2}{|c|}{ all other combinations }} & & 0.966 & 0.917 & $1^{\mathrm{e}}$ & $2 \times 10^{-7}$ \\
\hline & & DR15 negative & $\mathrm{N}=1005$ & $\mathrm{~N}=848$ & & \\
\hline+ & - & & 0.007 & 0.012 & $0.56(0.19-1.59)$ & 0.400 \\
\hline+ & 44 & & 0.013 & 0.046 & $0.27(0.13-0.52)$ & $3.3 \times 10^{-5}$ \\
\hline+ & 18 & & 0.013 & 0.037 & $0.33(0.16-0.67)$ & 0.0015 \\
\hline \multicolumn{2}{|c|}{ all other combinations } & & 0.968 & 0.913 & $1^{\mathrm{e}}$ & $5 \times 10^{-7}$ \\
\hline
\end{tabular}

${ }^{\text {a }}$ Presence of the indicated alleles

${ }^{\mathrm{b}}$ Frequency of individuals carrying the indicated alleles

${ }^{c}$ Calculated from $2 \times 2$ tables versus all the other possible allele combinations

${ }^{\mathrm{d}}$ HLA-B was considered as a triallelic locus including $H L A-B * 44, H L A-B * 18$ or none of them. The $A * 02-C w * 05$ individuals positive for both $B * 44$ and $B * 18$ were counted twice (cases $\mathrm{N}=2$, controls $\mathrm{N}=6$ in the total samples; cases $\mathrm{N}=1$, controls $\mathrm{N}=6$ in DR15 negative samples).

${ }^{\mathrm{e}}$ Reference for OR calculation. 
Table 3: Combinations of the "HLA-A*02- $H L A-C w^{*} 05$ " haplotype with $H L A-B$ in UK family trios

\begin{tabular}{|c|c|c|c|c|c|}
\hline \multicolumn{2}{|c|}{ HLA Haplotype ${ }^{a}$} & \multicolumn{2}{|c|}{ Frequency } & \multirow[b]{2}{*}{ OR $(95 \% \mathrm{CI})$} & \multirow[b]{2}{*}{$\mathrm{p}^{\mathrm{b}}$} \\
\hline$A * 02-C w * 05$ & $B * \mathrm{c}$ & $\begin{array}{r}\text { Transmitted } \\
\mathrm{N}=531 \mathrm{~d}\end{array}$ & $\begin{array}{c}\text { Non } \\
\text { transmitted } \\
\mathrm{N}=720^{\mathrm{d}}\end{array}$ & & \\
\hline+ & - & 0.0018 & 0.0041 & $0.43(0.01-5.40)$ & 0.641 \\
\hline+ & 44 & 0.028 & 0.075 & $0.36(0.19-0.67)$ & $5.5 \times 10^{-4}$ \\
\hline+ & 18 & 0.0094 & 0.0028 & $3.24(0.53-34.12)$ & 0.142 \\
\hline \multicolumn{2}{|c|}{ all other combinations } & 0.960 & 0.918 & $1^{e}$ & 0.0036 \\
\hline
\end{tabular}

${ }^{a}$ Haplotypes were calculated with the UNPHASED v 3.0.13 program using the "certain haplotype only" option.[17] All typing information, including DR, were utilised to deduce haplotypes.

${ }^{\mathrm{b}}$ Calculated from $2 \times 2$ tables versus all the other possible allele combinations.

${ }^{\mathrm{c}} H L A-B$ was considered as a triallelic locus including $H L A-B * 44, H L A-B * 18$ or none of them.

${ }^{\mathrm{d}} H L A-D R B 1 * 15$ negative haplotypes from 480 families.

${ }^{\mathrm{e}}$ Reference for OR calculation. 
Table 4 Logistic regression analysis in the Italian and UK population

\begin{tabular}{|c|c|c|c|c|c|c|c|c|c|}
\hline \multirow{3}{*}{$\begin{array}{r}\text { Population } \\
\text { ITALYd }\end{array}$} & \multirow{4}{*}{$\begin{array}{l}\text { Markers: } \\
\text { A*02 }\end{array}$} & \multicolumn{8}{|c|}{ OR (95\% CI) adjusted values for: } \\
\hline & & \multirow[t]{2}{*}{$D R B 1 * 15$} & \multicolumn{7}{|c|}{$D R B 1 * 15$ and: } \\
\hline & & & $A * 02$ & $C w * 05$ & $B * 44 / B * 12 \mathrm{a}$ & $B * 18$ & \multicolumn{2}{|c|}{ Two markers b } & \multirow[t]{2}{*}{$A * 02-C w * 05 \mathrm{c}$} \\
\hline ITALYd & & $\begin{array}{c}0.63 \\
(0.53-0.74) \\
p=6.8 \times 10^{-8}\end{array}$ & & $\begin{array}{c}0.63 \\
(0.53-0.75) \\
p=9.9 \times 10^{-8}\end{array}$ & $\begin{array}{c}0.63 \\
(0.53-0.75) \\
p=1.3 \times 10^{-7}\end{array}$ & $\begin{array}{c}0.62 \\
(0.52-0.74) \\
\mathrm{p}=4.4 \times 10^{-8}\end{array}$ & $\begin{array}{c}C w * 05 B * 44 \\
0.63 \\
(0.53-0.75) \\
p=1.4 \times 10^{-7}\end{array}$ & $\begin{array}{c}C w^{*} 05 B * 18 \\
0.63 \\
(0.53-0.74) \\
6.9 \times 10^{-8}\end{array}$ & \\
\hline & $\mathrm{Cw}^{*} 05$ & $\begin{array}{c}0.84 \\
(0.65-1.09) \\
p=0.2024\end{array}$ & $\begin{array}{c}0.88 \\
(0.68-1.14) \\
p=0.3445\end{array}$ & & $\begin{array}{c}0.94 \\
(0.72-1.23) \\
p=0.6503\end{array}$ & $\begin{array}{c}0.79 \\
(0.60-1.03) \\
p=0.0885\end{array}$ & $\begin{array}{c}A * 02 B * 44 \\
0.97 \\
(0.74-1.28) \\
\mathrm{p}=0.8593\end{array}$ & $\begin{array}{c}A * 02 \quad B * 18 \\
0.82 \\
(0.63-1.08) \\
\mathrm{p}=0.1555\end{array}$ & NA \\
\hline & $B * 44$ & $\begin{array}{c}0.70 \\
(0.56-0.88) \\
p=0.0026\end{array}$ & $\begin{array}{c}0.72 \\
(0.57-0.90) \\
\mathrm{p}=0.0051\end{array}$ & $\begin{array}{c}0.71 \\
(0.56-0.91) \\
p=0.0056\end{array}$ & & NA & $\begin{array}{c}A * 02 C w^{*} 05 \\
0.72 \\
(0.57-0.92) \\
\mathrm{p}=0.0082\end{array}$ & & $\begin{array}{c}0.79 \\
(0.62-1.00) \\
p=0.0503\end{array}$ \\
\hline & $B * 18$ & $\begin{array}{c}1.17 \\
(0.95-1.44) \\
p=0.1389\end{array}$ & $\begin{array}{c}1.20 \\
(0.97-1.49) \\
p=0.0817\end{array}$ & $\begin{array}{c}1.23 \\
(0.99-1.52) \\
p=0.0626\end{array}$ & NA & & $\begin{array}{c}A * 02 C w^{*} 05 \\
1.25 \\
(1.01-1.56) \\
\mathrm{p}=0.0415\end{array}$ & & $\begin{array}{c}1.25 \\
(1.01-1.55) \\
p=0.036\end{array}$ \\
\hline & $\begin{array}{l}A * 02- \\
C w * 05 \mathrm{c}\end{array}$ & $\begin{array}{c}0.39 \\
(0.27-0.57) \\
\mathrm{p}=4.7 \times 10^{-7}\end{array}$ & & & $\begin{array}{c}0.42 \\
(0.29-0.62) \\
p=7.3 \times 10^{-6}\end{array}$ & $\begin{aligned} & 0.37 \\
& (0.26- \\
& 0.54) \\
\mathrm{p}= & 1.5 \times 10^{-7}\end{aligned}$ & $\begin{array}{c}B * 44 B * 18 \mathrm{e} \\
0.38 \\
(0.26-0.56) \\
\mathrm{p}=6.5 \times 10^{-7}\end{array}$ & & \\
\hline $\mathbf{U K}{ }^{\mathrm{f}}$ & $A * 02$ & $\begin{array}{c}0.72 \\
(0.62-0.83) \\
\mathrm{p}=1.2 \times 10-5\end{array}$ & - & $\begin{array}{c}0.75 \\
(0.65-0.88) \\
p=0.0003\end{array}$ & $\begin{array}{c}0.74 \\
(0.64-0.87) \\
p=0.00013\end{array}$ & $\begin{array}{c}0.72 \\
(0.62-0.83) \\
p=1.3 \times 10^{-5}\end{array}$ & $\begin{array}{c}C w * 05 B * 12 \\
0.76 \\
(0.65-0.88) \\
p=0.0004\end{array}$ & $\begin{array}{c}C w * 05 B * 18 \\
0.76 \\
(0.65-0.88) \\
\mathrm{p}=0.0004\end{array}$ & NA \\
\hline
\end{tabular}




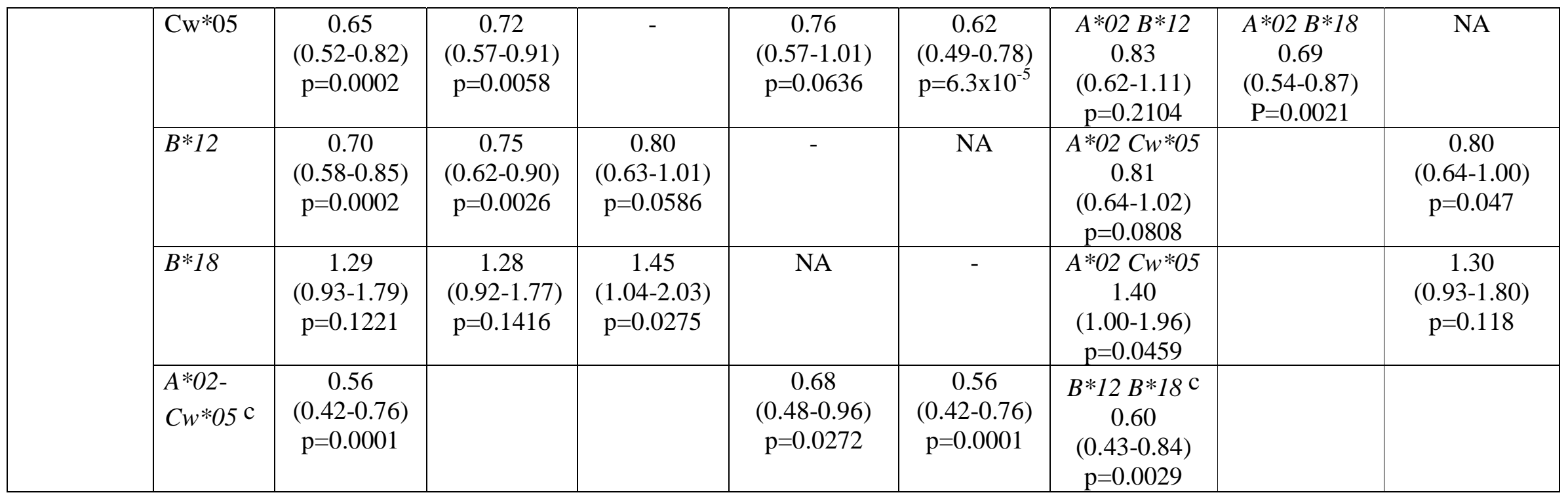

Italian individuals and UK haplotypes were categorized according to the presence or absence of the indicated alleles

Each marker in row is adjusted for markers in columns

p-values for adjusted models are obtained from Likelihood Ratio Test (LRT) comparing the likelihood of the two-gene additive vs the single marker model considering as single marker the marker used for adjustment.

$\mathrm{NA}=$ not applicable

a Results are referred to $B^{*} 44$ for the Italian individuals and $B * 12$ for the UK haplotypes

$\mathrm{b}$ values adjusted for DRB $1 * 15$ plus the indicated additional two class I markers

c subjects positive for both $\mathrm{A}^{*} 02$ and $\mathrm{Cw} * 05$ (A2+ and $\left.\mathrm{Cw} 5+\right)$.

d 1445 MS patients and 973 controls carrying the indicated alleles.

e since the two markers are allelic, they were considered as a single variable. Italian individuals and UK haplotypes were categorized according to the presence or absence of any of them.

f 2106 cases (860 transmitted haplotypes in family trios +1246 haplotypes from MS patients) and 1676 controls (860 non-transmitted haplotypes in family trios +816 haplotypes from controls). Haplotypes were calculated from individuals, fully typed for $H L A-A,-C w,-B$ and $-D R B 1$ loci, 
with the UNPHASED v 3.0.13 program using the "certain haplotype only" option in family trios and the "uncertain haplotypes" option in the case/control cohort.[17] All typing informations, including $D R$, were utilised to deduce haplotypes.

$\mathrm{NA}=$ not applicable 
Table 5:

Comparative analysis of all the possible combinations of the $\mathrm{A} * 02, C w^{* 05}$ and $B * 44$ alleles

\begin{tabular}{|c|c|c|c|c|c|c|c|c|}
\hline \multicolumn{3}{|c|}{ HLA alleles } & \multicolumn{6}{|c|}{ Population } \\
\hline \multirow[t]{2}{*}{$\begin{array}{c}A^{*} \\
02\end{array}$} & \multirow[t]{2}{*}{$\begin{array}{c}C w^{*} \\
05\end{array}$} & \multirow[t]{2}{*}{$\begin{array}{c}B^{*} \\
44 / 12^{\mathrm{a}}\end{array}$} & \multicolumn{2}{|c|}{$\begin{array}{c}\text { Italian } \\
\text { Case/control b }\end{array}$} & \multicolumn{2}{|c|}{$\begin{array}{c}\text { UK } \\
\text { Family trios }\end{array}$} & \multicolumn{2}{|c|}{$\begin{array}{c}\text { UK } \\
\text { Combined case/control anc } \\
\text { family trios } \mathrm{d}\end{array}$} \\
\hline & & & $\mathrm{OR}^{\mathrm{e}}$ & P value $^{f}$ & $\mathrm{OR}^{\mathrm{e}}$ & P value $^{f}$ & $\mathrm{OR}^{\mathrm{e}}$ & $P$ value \\
\hline+ & - & - & $\begin{array}{c}\mathbf{0 . 6 3} \\
(0.50-0.78)\end{array}$ & 0.0007 & $\begin{array}{c}0.80 \\
(0.59-1.08)\end{array}$ & 0.509 & $\begin{array}{c}\mathbf{0 . 6 5} \\
(0.49-0.84)\end{array}$ & 0.0099 \\
\hline- & + & - & $\begin{array}{c}\mathbf{3 . 4 1} \\
(1.74-7.32)\end{array}$ & $1.7 \times 10^{-6}$ & $\begin{array}{c}1.18 \\
(0.42-3.27)\end{array}$ & 0.680 & $\begin{array}{c}1.30 \\
(0.58-2.93)\end{array}$ & 0.335 \\
\hline- & - & + & $\begin{array}{c}0.62 \\
(0.41-0.92)\end{array}$ & 0.182 & $\begin{array}{c}0.79 \\
(0.49-1.29)\end{array}$ & 0.763 & $\begin{array}{c}0.75 \\
(0.49-1.13)\end{array}$ & 0.561 \\
\hline- & + & + & $\begin{array}{c}0.77 \\
(0.40-1.47)\end{array}$ & 0.977 & $\begin{array}{c}0.49 \\
(0.24-1.00)\end{array}$ & 0.108 & $\begin{array}{c}\mathbf{0 . 3 7} \\
(0.19-0.72)\end{array}$ & 0.0087 \\
\hline+ & - & + & $\begin{array}{c}0.74 \\
(0.45-1.23)\end{array}$ & 0.866 & $\begin{array}{c}0.62 \\
(0.25-1.50)\end{array}$ & 0.538 & $\begin{array}{c}0.83 \\
(0.33-2.13)\end{array}$ & 0.856 \\
\hline+ & + & - & $\begin{array}{c}\mathbf{0 . 3 6} \\
(0.19-0.67)\end{array}$ & 0.007 & $\begin{array}{c}1.42 \\
(0.36-5.94)\end{array}$ & 0.543 & $\begin{array}{c}0.39 \\
(0.07-1.74)\end{array}$ & 0.346 \\
\hline+ & + & + & $\begin{array}{c}\mathbf{0 . 2 2} \\
(0.11-0.44)\end{array}$ & $3.3 \times 10^{-5}$ & $\begin{array}{c}\mathbf{0 . 3 3} \\
(0.17-0.61)\end{array}$ & $5.5 \times 10^{-4}$ & $\begin{array}{c}\mathbf{0 . 5 3} \\
(0.32-0.86) \\
\end{array}$ & 0.044 \\
\hline
\end{tabular}

${ }^{\text {a }}$ Results are referred to $B^{*} 44$ for the Italians and the UK family trios and $B^{*} 12$ for the combined UK case/control and family trios. $H L A-B * 18$ was not considered in this table; therefore $H L A-B * 18$ positives are included among $B^{*} 44 / 12$ negatives.

${ }^{\mathrm{b}} 1005$ DR15 negative MS patients and 848 DR15 negative controls carrying the indicated alleles.

c 531 DR15 negative transmitted and 720 DR15 negative non-transmitted haplotypes from 480 family trios.

d 784 cases (derived from 262 transmitted haplotypes in DR15 negative families + 522 haplotypes from DR15 negative MS patients) and 848 controls (derived from 262 non-transmitted haplotypes in DR15 negative families. + 586 haplotypes from DR15 negative controls). Haplotypes 
were calculated with the UNPHASED v 3.0.13 program using the "certain haplotype only" option in family trios and the "uncertain haplotypes" option in the case/control cohort.[17] All typing information, including $D R$, were utilised to deduce haplotypes.

${ }^{\mathrm{e}}$ The $A * 02-, C w * 05$-, $B * 44 / 12$ - combination was the reference for OR calculation.

${ }^{\mathrm{f}}$ Calculated from $2 \times 2$ tables versus all the other possible allele combinations.

Significantly protective allele combinations are bolded. 
Supplementary Table 1

$A * 02, C w^{*} 05$ and $B^{*}(44 / 18)$ phenotypic combinations in Italian DR15 negative samples

\begin{tabular}{cccccccc}
\hline \multicolumn{7}{c}{$H L A$ phenotype } & \multicolumn{2}{c}{ Frequency } & OR & $95 \%$ CI & $\mathrm{p}^{\mathrm{c}}$ \\
$A * 02$ & $C w^{*} 05$ & $B^{* \mathrm{~d}}$ & $\mathrm{MS}$ patients & Controls & & & \\
\hline- & - & - & 0.433 & 0.360 & $1 \mathrm{f}$ & 1 & 0.0016 \\
- & - & 44 & 0.056 & 0.072 & 0.64 & $0.43-0.97$ & 0.1823 \\
- & - & 4402 & 0.022 & 0.021 & 0.91 & $0.45-1.85$ & 0.948 \\
- & - & 4403 & 0.031 & 0.046 & 0.57 & $0.34-0.97$ & 0.886 \\
- & - & 18 & 0.092 & 0.061 & 1.24 & $0.84-1.83$ & 0.0196 \\
- & + & - & 0.010 & 0.001 & 7.01 & $0.99-305$ & 0.0319 \\
- & + & 44 & 0.024 & 0.025 & 0.80 & $0.42-1.53$ & 0.9774 \\
- & + & 4402 & 0.021 & 0.021 & 0.87 & $0.43-1.78$ & 0.934 \\
- & + & 4403 & 0.0030 & 0.0013 & 2.10 & $0.17-110.8$ & 0.631 \\
- & + & 18 & 0.050 & 0.015 & 2.70 & $1.39-5.32$ & $8.0 \times 10^{-}-05$ \\
+ & - & - & 0.212 & 0.276 & 0.64 & $0.50-0.81$ & 0.0016 \\
+ & - & 44 & 0.040 & 0.042 & 0.78 & $0.47-1.28$ & 0.8656 \\
+ & - & 4402 & 0.015 & 0.013 & 0.96 & $0.41-2.26$ & 0.905 \\
+ & - & 4403 & 0.022 & 0.025 & 0.73 & $0.38-1.43$ & 0.761 \\
+ & - & 18 & 0.068 & 0.077 & 0.73 & $0.50-1.08$ & 0.5115 \\
+ & + & - & 0.007 & 0.012 & 0.49 & $0.17-1.42$ & 0.4001 \\
+ & + & 44 & 0.013 & 0.046 & 0.23 & $0.12-0.46$ & $3.3 \times 10^{-} 05$ \\
+ & + & 4402 & 0.013 & 0.031 & 0.35 & $0.16-0.72$ & 0.011 \\
+ & + & 4403 & 0.0010 & 0.0072 & 0.12 & $0-0.97$ & 0.051 \\
+ & + & 18 & 0.013 & 0.037 & 0.29 & $0.14-0.59$ & 0.0015 \\
\hline
\end{tabular}

${ }^{a}$ Presence of the indicated alleles.

${ }^{\mathrm{b}}$ Frequency of individuals carrying the indicated alleles.

${ }^{\mathrm{c}}$ Calculated from $2 \times 2$ tables versus all the other possible allele combinations. 
${ }^{\mathrm{d}} H L A-B$ was considered as a triallelic locus including $H L A-B * 44, H L A-B * 18$ or none of them. Individuals positive for both $B * 44$ and $B * 18$ were counted twice (Cases $\mathrm{N}=16$; Controls $\mathrm{N}=20$ ).

e 995 DR15 negative patients and 827 DR15 negative controls were typed for $B^{* 44}$ subtypes $B^{* 4402}$ and $B^{* 4403 .}$

${ }^{\mathrm{f}}$ Reference for OR calculation. 
Supplementary Table 2

$D R B 1 * 15$ negative haplotypic combinations in $\mathrm{UK}$ family trios

\begin{tabular}{|c|c|c|c|c|c|c|c|}
\hline \multicolumn{3}{|c|}{ Haplotype ${ }^{a}$} & \multicolumn{2}{|c|}{ Frequency } & \multirow[t]{2}{*}{ OR } & \multirow[t]{2}{*}{$95 \% \mathrm{CI}$} & \multirow[t]{2}{*}{$\mathrm{p}^{\mathrm{b}}$} \\
\hline$A * 02$ & $C w * 05$ & $B^{*}$ & $\begin{array}{l}\text { Transmitted } \\
\mathrm{N}=531^{\mathrm{c}}\end{array}$ & $\begin{array}{l}\text { Non transmitted } \\
\qquad \mathrm{N}=720^{\mathrm{c}}\end{array}$ & & & \\
\hline - & - & - & 0.637 & 0.556 & $1^{d}$ & 1 & 0.0048 \\
\hline - & - & 44 & 0.055 & 0.064 & 0.75 & $0.45-1.25$ & 0.57 \\
\hline - & - & 18 & 0.021 & 0.013 & 1.45 & $0.55-3.84$ & 0.36 \\
\hline - & + & - & 0 & 0.003 & 0 & $0-6.33$ & 0.51 \\
\hline - & + & 44 & 0.024 & 0.043 & 0.5 & $0.24-1$ & 0.11 \\
\hline - & + & 18 & 0.017 & 0.010 & 1.52 & $0.51-4.58$ & 0.38 \\
\hline+ & - & - & 0.186 & 0.201 & 0.81 & $0.6-1.1$ & 0.56 \\
\hline+ & - & 44 & 0.015 & 0.022 & 0.59 & $0.23-1.49$ & 0.48 \\
\hline+ & - & 18 & 0.006 & 0.007 & 0.71 & $0.11-3.68$ & 1 \\
\hline+ & + & - & 0.002 & 0.004 & 0.39 & $0.01-4.94$ & 0.64 \\
\hline+ & + & 44 & 0.028 & 0.075 & 0.33 & $0.17-0.61$ & $5.5 \times 10^{-4}$ \\
\hline+ & + & 18 & 0.009 & 0.003 & 2.96 & $0.48-31.21$ & 0.14 \\
\hline
\end{tabular}

" Haplotypes were deduced with the UNPHASED v 3.0.13 program using the "certain haplotype only" option.[17] The complete $H L A-A, B, C, D R$ typing was considered for haplotype reconstruction.

${ }^{\mathrm{b}}$ Calculated from $2 \times 2$ tables versus all the other possible allele combinations.

${ }^{c} D R B 1 * 15$ negative haplotypes from 480 families.

${ }^{\mathrm{d}}$ Reference for OR calculation. 
Supplementary Table 3

Haplotypic combinations in UK case/control DR15 negative samples.

\begin{tabular}{|c|c|c|c|c|c|c|c|}
\hline \multicolumn{3}{|c|}{ Haplotype ${ }^{a}$} & \multicolumn{2}{|c|}{ Frequency } & \multirow[t]{2}{*}{ OR } & \multirow[t]{2}{*}{$95 \%$ CI } & \multirow[t]{2}{*}{$\mathrm{p}^{\mathrm{b}}$} \\
\hline$A^{*} 02$ & $C w * 05$ & $B^{*}$ & $\begin{array}{c}\text { MS } \\
\text { patients } \\
\mathrm{N}=522\end{array}$ & $\begin{array}{l}\text { Controls } \\
\mathrm{N}=586\end{array}$ & & & \\
\hline - & - & - & 0.657 & 0.567 & $1^{\mathrm{c}}$ & 1 & 0.0025 \\
\hline- & - & 12 & 0.069 & 0.072 & 0.83 & $0.52-1.36$ & 0.954 \\
\hline - & - & 18 & 0.021 & 0.017 & 1.06 & $0.41-2.75$ & 0.789 \\
\hline- & + & - & 0.004 & 0.002 & 1.94 & $0.10-114.55$ & 0.604 \\
\hline- & + & 12 & 0.011 & 0.032 & 0.31 & $0.10-0.81$ & 0.0324 \\
\hline- & + & 18 & 0.021 & 0.012 & 1.52 & $0.54-4.40$ & 0.336 \\
\hline+ & - & - & 0.149 & 0.212 & 0.61 & $0.44-0.85$ & 0.0094 \\
\hline+ & - & 12 & 0.013 & 0.009 & 1.36 & $0.37-5.47$ & 0.623 \\
\hline+ & - & 18 & 0.010 & 0.009 & 0.97 & $0.22-4.25$ & 1.000 \\
\hline+ & + & - & 0.002 & 0.002 & 0.97 & $0.01-76.21$ & 1.000 \\
\hline+ & + & 12 & 0.042 & 0.061 & 0.59 & $0.33-1.06$ & 0.192 \\
\hline+ & + & 18 & 0 & 0.007 & 0 & $0-1.48$ & 0.127 \\
\hline
\end{tabular}

"Haplotypes were deduced by the UNPHASED v 3.0.13 program using the "uncertain haplotypes" option.[17] Also the information of the complete DR typing was considered for haplotype reconstruction.

${ }^{\mathrm{b}}$ Calculated from $2 \times 2$ tables versus all the other possible allele combinations.

${ }^{c}$ Reference for OR calculation. 
Supplementary Table 4

Combined analysis of haplotypic combinations derived from UK DR15 negative family trios and case/controls

\begin{tabular}{|c|c|c|c|c|c|c|c|}
\hline \multicolumn{3}{|c|}{ Haplotype ${ }^{a}$} & \multicolumn{2}{|c|}{ Frequency } & \multirow[t]{2}{*}{ OR } & \multirow[t]{2}{*}{$95 \% \mathrm{CI}$} & \multirow[t]{2}{*}{$\mathrm{p}^{\mathrm{b}}$} \\
\hline$A^{*} 02$ & $C w * 05$ & $B^{*}$ & $\begin{array}{c}\mathrm{MS} \\
\text { patients } \\
\mathrm{N}=784^{\mathrm{c}}\end{array}$ & $\begin{array}{l}\text { Controls } \\
\mathrm{N}=848^{\mathrm{d}}\end{array}$ & & & \\
\hline- & - & - & 0.663 & 0.565 & $1^{\mathrm{e}}$ & 1 & $5.7 \times 10^{-05}$ \\
\hline- & - & 12 & 0.0612 & 0.0696 & 0.75 & $0.49-1.14$ & 0.56 \\
\hline- & - & 18 & 0.0179 & 0.013 & 1.17 & $0.5-2.79$ & 0.55 \\
\hline- & + & - & 0.0025 & 0.0035 & 0.61 & $0.05-5.39$ & 1 \\
\hline - & + & 12 & 0.018 & 0.041 & 0.37 & $0.19-0.72$ & 0.0087 \\
\hline- & + & 18 & 0.019 & 0.011 & 1.54 & $0.63-3.83$ & 0.22 \\
\hline+ & - & - & 0.156 & 0.206 & 0.64 & $0.49-0.84$ & 0.0096 \\
\hline+ & - & 12 & 0.013 & 0.013 & 0.84 & $0.33-2.14$ & 0.86 \\
\hline+ & - & 18 & 0.008 & 0.008 & 0.79 & $0.22-2.77$ & 0.89 \\
\hline+ & + & - & 0.0013 & 0.004 & 0.31 & $0.01-3.84$ & 0.63 \\
\hline+ & + & 12 & 0.038 & 0.061 & 0.53 & $0.32-0.87$ & 0.044 \\
\hline+ & + & 18 & 0.0026 & 0.005 & 0.46 & $0.04-3.23$ & 0.69 \\
\hline
\end{tabular}

a Haplotypes were calculated with the UNPHASED v 3.0.13 program using the "uncertain haplotypes" option.[17] Also the information of the complete DR typing was considered for haplotype reconstruction.

${ }^{\mathrm{b}}$ Calculated from $2 \times 2$ tables versus all the other possible allele combinations.

${ }^{\mathrm{c}} 262$ transmitted haplotypes in DR15 negative families + 522 haplotypes from DR15 negative MS patients.

d 262 non-transmitted haplotypes in DR15 negative families + 586 haplotypes from DR15 negative controls.

${ }^{\mathrm{e}}$ Reference for OR calculation. 


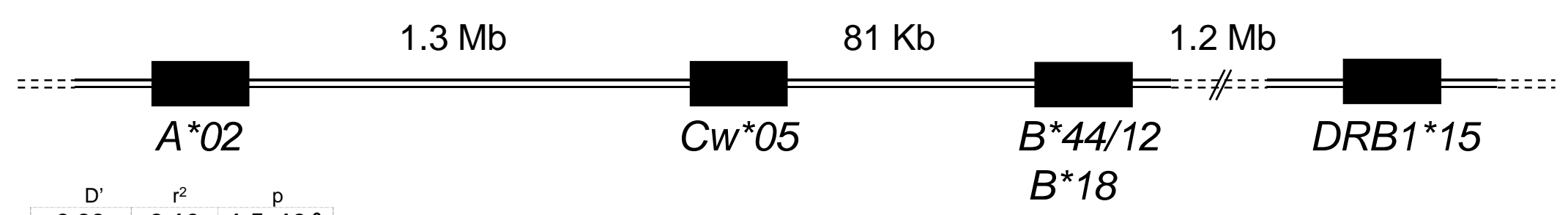

\begin{tabular}{|c|c|c|c|c|c|c|c|c|}
\hline \multirow{3}{*}{$C w^{*} 05$} & \multicolumn{2}{|r|}{$D^{\prime}$} & \multicolumn{2}{|l|}{$r^{2}$} & & & & \\
\hline & $\mathrm{IT}$ & 0.39 & 0.16 & $1.5 \times 10^{-6}$ & & & & \\
\hline & UK & 0.46 & 0.24 & $<10^{-7}$ & & & & \\
\hline & & $D^{\prime}$ & $r^{2}$ & $\mathrm{p}$ & & $D^{\prime}$ & $r^{2}$ & $p$ \\
\hline & IT & 0.030 & 0.014 & ns & IT & 0.46 & 0.36 & $<10^{-7}$ \\
\hline $44 / 12$ & UK & 0.26 & 0.17 & $<10^{-7}$ & UK & 0.85 & 0.66 & $<10^{-7}$ \\
\hline$B^{*}$ & & $D^{\prime}$ & $r^{2}$ & $p$ & & $D^{\prime}$ & $r^{2}$ & $\mathrm{p}$ \\
\hline 18 & IT & 0.19 & 0.095 & ns & $\mathrm{IT}$ & 0.26 & 0.20 & $<10^{-7}$ \\
\hline & UK & -0.008 & 0.012 & ns & UK & 0.22 & 0.12 & $1.7 \times 10^{-5}$ \\
\hline
\end{tabular}

\begin{tabular}{|c|c|c|c|}
\hline & $D^{\prime}$ & $r^{2}$ & p \\
\hline IT & -0.004 & 0.041 & ns \\
\hline \multirow[t]{2}{*}{ UK } & -0.012 & 0.12 & $7.0 \times 10^{-7}$ \\
\hline & $D^{\prime}$ & $r^{2}$ & $p$ \\
\hline IT & -0.0005 & 0.005 & ns \\
\hline UK & 0.049 & 0.023 & ns \\
\hline
\end{tabular}

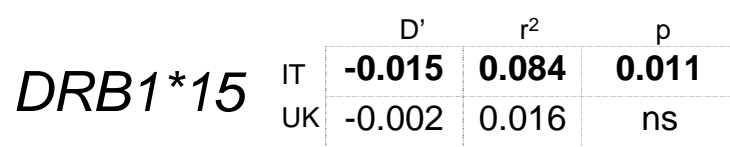

\begin{tabular}{l|c|cc}
\multicolumn{1}{c}{} & $\mathrm{D}^{\prime}$ & $\mathrm{r}^{2}$ & $\mathrm{p}$ \\
IT & $\mathbf{0 . 0 0 4}$ & 0.004 & $\mathrm{~ns}$ \\
UK & $\mathbf{- 0 . 0 0 8}$ & $\mathbf{0 . 1 1}$ & $\mathbf{2 . 4 \times 1 0 ^ { - 4 }}$
\end{tabular}

